\title{
Can large retailers localize supply chains? A case analysis of the challenges facing one Canadian retailer
}

\author{
Doug McCallum, ${ }^{\mathrm{a}}$ Alissa Mae Campbell, ${ }^{\mathrm{a}}$ and Rod MacRae ${ }^{\text {* }}$ \\ York University
}

Submitted October 1, 2013 / Revised January 10 and January 29, 2014 / Accepted January 30, 2014 /

Published online March 19, 2014

Citation: McCallum, D., Campbell, A. M., \& MacRae, R. (2014). Can large retailers localize supply chains?

A case analysis of the challenges facing one Canadian retailer. Journal of Agriculture, Food Systems, and

Community Development, 4(2), 163-176. http://dx.doi.org/10.5304/jafscd.2014.042.015

Copyright (C) 2014 by New Leaf Associates, Inc.

\begin{abstract}
Extensive access to a major Canadian retailer (referred to as the Company) provided an opportunity to understand more fully its challenges when buying local food. Many of the Company volume and quality requirements of vendors are difficult to meet because they require a scale sophistication that is typically absent for local growers. Particularly challenging are the needs to lengthen product life, coordinate transport, and aggregate supply. Liability associated with spoiled product is especially onerous for small growers. Using a value supply-chain framework (Stevenson \& Pirog, 2008), we conclude that the steps taken by the retailer toward localization will not be successful without significant investments in product differentiation, the financial health of their supplier base, strategic alliances, and shared governance.
\end{abstract}

\section{Keywords}

localization, national food retailer, supply chain, value chain, Canada

\footnotetext{
${ }^{\text {a }}$ Faculty of Environmental Studies, York University.
}

* Corresponding author: 4700 Keele Street, Toronto, Ontario M3J1P3 Canada; +1-416-736-2100x22116; rmacrae@,yorku.ca

\section{Introduction}

Rising concerns regarding the health and environmental impacts of food have caused both farmers and consumers to create and support more spatially localized food networks, to reduce intermediaries ${ }^{1}$ and create direct exchange. By differentiating themselves from conventional food chains, farmers hope to obtain a greater percentage of the food consumer dollar (Howard \& Allen, 2006) or enhance access to domestic consumers. Equally important, as stated by Kneen (1993), is the disassociation between consumers and growers that is created by long-distance movements of food:

What is mourned as farmers depart the land, as the government and its Market Economy agents dismantle the infrastructure of rail lines and schools and public services, is the possibility of community. (p. 73)

Related to this, many food producers and processors support a production and processing

\footnotetext{
${ }^{1}$ Outlined by Kneen (1993, p. 26) as "exporters at one end to retailers at the other, and including the manufacturers of farm 'inputs' like hybrid seeds and agro-toxins."
} 
system that is different from "mass produced" food.

The notion of "difference" becomes critical to the process of reconnection: creating a difference in "quality"'between specific products and mass-produced products; creating a difference between geographical anonymity in food provenance and territorial specificity; and creating a difference in the way certain foods are produced.

(Ilbery, Morris, Buller, Maye, \& Kneafsey, 2005, p. 118)

This "process of reconnection" has the promise of allowing farmers to take home a greater return than is provided by conventional food markets, increasing consumer confidence in food production, and placing a greater focus on rural development, thus strengthening a local, sustainable food system (Winter, 2003).

Having started with small and medium-sized enterprises, the localization process has attracted the interest of mainstream supply-chain actors, including large retailers. The purpose of this paper is to examine the necessary conditions for the inclusion of locally produced fruits and vegetables in the supply chains of major grocery retailers in Canada. Canada's food retail environment is dominated by three national chains that control, according to differing estimates, from 62 percent (Industry Canada, 2013) to 75 percent (estimated from Agriculture and Agri-Food Canada, 2009) of the food retail market place. ${ }^{2}$ Although these retailers are smaller in absolute terms than the largest U.S. food retailers, their relative market position is much stronger. Consequently, our working hypothesis is that retailers of this market size will face some challenges that are not entirely the same as small to medium-size retailers. Few studies have looked at the issues from the perspective of a major retailer, instead examining issues for small to medium-size producers (e.g., Barham, 2009; Day-Farnsworth, McCown, Miller, \& Pfeiffer, 2009), intermediate aggregators, distributors and

${ }^{2}$ In 2013, Loblaw purchased Shopper's Drug Mart and Empire (Sobey's) purchased Canadian holdings of Safeway. retailers (e.g., Diamond \& Barham, 2012; King et al., 2010), or emerging food hub structures. ${ }^{3}$

To this end, a review of the relevant supplychain transformation literature was undertaken and a close case study was conducted of a major grocery retailer in Canada, henceforth referred to as the "Company." We report on how the Company purchases, organizes, distributes, and sells locally grown fruits and vegetables throughout stores across Canada, in order to gain a fuller appreciation for the challenges of localization. We analyze the main obstacles facing the Company, how and why those problems have developed, and some suggestions for improving the flow of locally produced food into the supply chain in ways that are consistent with the values and attitudes associated with the localization phenomenon. ${ }^{4}$

We used publically available information (grocery industry newsletters, annual reports, media reviews, and government documents), corporate documents supplied by the Company, and data collected through the field study. Given the limited number of national retailers, the Company was selected based on existing contacts of the lead author. The lead author toured distribution facilities and stores, had access to the Company's head office staff, held group interviews with regional distribution center staff in a variety of capacities, was granted access to confidential corporate reports, and held a series of interviews with the individual in charge of the produce business unit at the national level. Field notes were recorded, from which patterns were identified that became the basis for triangulation with the other data sources.

\section{Localization: A Review of the Supply Chain Transformation Literature}

There is, of course, much debate about how to define local foods. For this analysis, it is sufficient to categorize local as subnational food supply chains, conforming to provincial boundaries or smaller regions (Louden \& MacRae, 2010). Agriculture and Agri-food Canada (2003-2011)

\footnotetext{
${ }^{3}$ See the special issue on food hubs in Local Environment 18(5).

${ }^{4}$ Note that we are not providing a broader critique of the merits of large retailer participation in local food chains.
} 
reports that roughly 70 percent of Canadian consumption is met by domestic production and that 50 percent of domestic production is exported, particularly live animals, bulk grains, and oilseeds. There are reports on local food initiatives (Canadian Organic Growers, 2007), but limited data on how much food flows through subnational chains. Agriculture and Agri-food Canada (2003-2011) also reported that only about 1 percent of retail food sales were direct marketed, but direct marketing is a small subset of local distribution. Canada's supply-managed commodities (primarily dairy, eggs, chicken and turkey) are largely organized provincially, with restrictions on crossborder trade. British Columbia estimated that its producers provided 48 percent of the food consumed in the province (British Columbia Ministry of Agriculture and Lands, 2006). Undoubtedly the sector is larger than these statistics suggest, but its exact size is unknown.

Despite confusion about what local means, food system localization has gained considerable traction among academics and non-academics alike, including an increasing number of policy-makers. The academic discussion has centered on the environmental, social, and economic implications of local food systems, both positive (NorbergHodge, Merrifield, \& Gorelick, 2002; Pirog, Van Pelt, Enshayon, \& Cook, 2001) and sometimes critical (Born \& Purcell, 2006; Edwards-Jones et al., 2008; Weber \& Matthews, 2008). Other studies have focused on the social "embeddedness" of localized supply chains and the communitybuilding impacts of reducing the "social" distance between producers and consumers (Hinrichs, 2000; Sage, 2003). An essential part of this perspective is the information flows that distinguish "short food supply chains" from the conventional food system (Feenstra, Allen, Hardesty, Ohmart, \& Perez, 2011). Marsden, Banks, and Bristow (2000) explain that "A key characteristic of short food supply chains is their capacity to re-socialize or re-spatialize food, thereby allowing the consumer to make valuejudgments about the relative desirability of foods on the basis of their own knowledge, experience, or perceived imagery" (p. 425). Finally, based on the local economic contributions of local food supply chains, some authors have suggested localization as an effective rural development strategy (Renting, Marsden, \& Banks, 2003).

On the ground, this has resulted in the development of alternative avenues for the distribution of locally produced food; two complementary concepts, alternative food networks (AFNs) and short food supply chains (SFSCs), have been used to describe these avenues. AFNs and SFSCs are directly tied to the re-localization movement and have been discussed broadly as concerted responses to a crisis in conventional agriculture (Feagan, 2007). The conceptualization of AFNs can be located within the recent transition from speaking about food systems to a new tendency of focusing on food networks. This tendency reflects a shift towards thinking relationally, in terms of "flows, processes and relationships" that make up a system, rather than of a system as a static entity (Kneafsey, 2010, p. 3). Speaking in terms of networks may also act as a language to navigate the use of nuanced terms, such as "local" and "alternative," that fail to fully capture the complexities and "contested and contingent relationships" characterizing the ways in which food is made available (Kneafsey, 2010, p. 3).

On the consumer side, the emergence of alternative systems of food provision has been driven by increased public concern over issues such as food safety, animal welfare, and the environment (Renting et al., 2003). Widespread food safety scares, such as those stemming from outbreaks of salmonella and bovine spongiform encephalopathy (BSE), have contributed in particular to growing distrust of the conventional food system. Pressures on the producer side have also contributed to the emergence of alternative food distribution avenues. With an income squeeze being felt by small and medium-size farmers, innovative ways of increasing farm revenue have become increasingly attractive (Renting et al., 2003). In this sense, AFNs and SFSCs are viewed as mechanisms to improve farm revenues by increasing the value-added qualities of farm products, as well as by reorganizing the supply chain such that farmers may capture a greater share of the retail dollar.

Renting et al. (2003) note that as AFNs become more widespread and increasingly diverse, 
"there is an urgent need for more specific concepts that help us grasp the variability of AFNs and begin to provide an improved 'toolbox' with which to explore the heterogeneity of AFNs" (p. 394).

The authors state that "AFNs, by their very nature, employ different social constructions and equations with ecology, locality, region, quality convention, and consumer cultures" (p. 394). Thus, while broader analyses of alternative food networks can provide us with a sense of the ways they collectively respond to the crisis in conventional agriculture, understanding the spatial and social distinctiveness of different models of AFNs is necessary to discern their strengths and weaknesses and the diversity of goals to which they may be suited.

SFSCs offer a second conceptual phrase for similarly describing alternative avenues of food distribution. While conceptually very similar to alternative food networks, SFSCs center specifically around the food chain dimension, juxtaposing alternative "short" chains against the "long, complex and rationally organized industrial chains" (Marsden et al., 2000). In deciphering the semantic differences between such emerging concepts, Renting et al. (2003) suggest that the "SFSC concept is more specific than AFNs, and, rather, covers (the interrelations between) actors who are directly involved in the production, processing, distribution, and consumption of new food products" (p. 394). Significantly, a focus on the supply chain as the center of analysis recognizes the role supply-chain reconfiguration plays in the development of alternative food networks.

Renting, Marsden, and Banks (2003) use two interrelated dimensions to explore the morphology of short food supply chains: (1) the organizational structure and the specific mechanisms utilized to extend relations in time and space; and (2) the different qualities of the definitions and conventions involved in the construction and operation of SFSCs. On the basis of the first dimension, the authors identify three main types of short food supply chains:

- Face-to-face: Consumers purchase products directly from a producer or processor, ensuring authenticity and trust through personal interaction.
- Proximate: Consumers purchase products from retail outlets within the region where the product was produced and are made aware of the local nature of the product at the point of sale.

- Extended: Consumers purchase products outside their region of production; however, the products themselves nonetheless carry information regarding the place of production.

(Renting et al., 2003, pp. 399-400)

Besides their organizational structure, SFSCs are also distinguished by the product information they convey to consumers, making them particularly relevant to localized chains. Because information flows are so effectively maintained within SFSCs, consumers are able to connect with the place of production as well as to the production practices employed; this allows for product differentiation upon which consumers may make value-driven decisions, as well as for producers to potentially command price premiums based on the value associated with the embedded information (Marsden et al., 2000). What distinguishes local food supply chains from mainstream supply chains, according to a U.S. Department of Agriculture (USDA) research report, is the former's use and conveyance of information to allow consumers to recognize products as local; through this informational exchange, local food supply chains "strive to establish a bond between the producer and the consumer" (King et al., 2010).

Another concept potentially applicable to major retailer involvement in localization is that of transitional food system change: piggybacking on the dominant system to advance desirable changes in supply chains (Bloom \& Hinrichs, 2011). This is part of the value chain approach (Stevenson \& Pirog, 2008) that builds on some aspects of traditional supply chain analysis (such as scale and efficiency), but with the added dimension of values-based production and distribution (in this case localization and its potential benefits).

While local food systems are growing and strengthening rapidly, this growth has faced a number of constraints. In the report Bringing Local Food Home, the Canadian Institute for Environ- 
mental Law and Policy notes that "despite the strong demand for local food and a robust seasonal supply, the market is not yet delivering local food to the extent that consumers want it due to a variety of systemic barriers" (Carter-Whitney, 2008, p. 1). One of the most common systemic barriers is the lack of "infrastructure needed to locate and coordinate the communication, planning, processing, tracking, and distribution of farm produce to institutions" (Vogt \& Kaiser, 2008, p. 248). Lack of suitable infrastructure has likewise been identified in numerous other cases (Bittner, Day-Farnsworth, Miller, Kozub, \& Gollnik, 2011; Day-Farnsworth et al., 2009; Feenstra et al., 2011; Food Links UK, 2006).

The major retailers have, of course, significant infrastructure, but is it suitable for meeting the needs of local producers? Can major retailers participate in localized supply chains without compromising either the integrity or value of the product? Further, can they provide a sense of connection to people and place - consistent with the efforts of other AFNs and SFSCs - that consumers seek through the purchase of local food? We explore these questions below in the context of the produce supply chains of a major retailer. We first describe how the Company operates and understands the logistics in its supply chains, and then provide our analysis of the implications for localization.

\section{The Company}

\section{Organization of the Produce Business Unit}

Broadly, the Company is broken up into a series of business units or management categories, including grocery, meat, dairy, and produce. Each of these units has two aspects built into its design: first, to act, essentially, as a separate business responsible for creating, implementing, and evaluating policies that exist to generate revenue and improve efficiency; and second, to act as a member of the overall business, exposed and subject to the decisions made by the executive branch of the Company. This allows each unit, in theory, the flexibility to make policies to adapt to new changes in the business environment or to react to the introduction of new government regulations.
Through this structure, each unit has both the liability protection of the Company and the flexibility to make decisions without waiting for approval from all departments at the corporate level. This paper will focus on the actions of the produce business unit only, because produce raises interesting issues, is a priority for environmental improvements related to localization (MacRae, Cuddeford, Young, \& Matsubuchi-Shaw, 2013), and regulatory and corporate responsibilities are sufficiently different from one unit to another, making the study of more than one business unit at a time challenging.

Throughout the season in which the bulk of "local food" sales take place, the Company promotes products by region. Within the produce business unit of the Company, there are three primary regions that are used to manage the unit. Quebec and Atlantic Canada make up the first, then Ontario, and Western Canada (which includes the prairies as well as the west coast). For the purpose of this paper, the term "local food" will mean any product that is grown and sold within each of the regions mentioned above. However, it is important to note that according to the Company, only people in Ontario consider produce shipped in from other provinces not to be "local food." The remainder of the country is happy to consider product produced in other provinces to be local, except produce from Ontario. Consequently, the Company tends to take a more regional approach to local food definition as compared to the literature.

The produce business unit is based around three separate sub-units (A, B, C), each of which is responsible for a particular grouping of products. Each sub-unit is responsible for purchasing, generating revenue, and reducing costs in order to meet the unit quarterly and yearly goals. Each subunit is managed by a category manager and assistant category manager, who are responsible for tracking and procuring inventory for the distribution centers. Through this model, these managers work with vendors to receive better pricing based on sales volume and negotiation.

The distribution center acts as both the customer of vendors, and vendor to the retail stores. In this model, communication between 
stores and the category managers is central, because without adequate communication the manager's capacity to make informed decisions regarding purchases is reduced. Generally, the category managers make decisions about the quantity of produce required based on how much product is in the store (on shelves and in back), upcoming promotions, flyers, and predictions based on past or seasonal sales. Within a distribution center visited as part of the field study, communication between the quality assurance staff and the category managers was considered to be a factor in ensuring that product is moved efficiently with minimum waste.

While purchasing locally has a number of unique problems (to be addressed later in this section), the process of accepting produce into the Company's supply chain is the same as any other product. Therefore, it is useful to discuss the broad framework of the operations side of the produce business unit prior to discussing the particular issues associated with locally sourced foods.

\section{How Produce Is Purchased, Evaluated, and Redistributed}

For the Company, supply-chain organization and management are two of the key components of successfully purchasing, evaluating, and distributing fresh fruits and vegetables. There are numerous general challenges, including waste management, shipping problems, border crossings, tracking temperature, promotion timing, food safety, and inspections. Assuming that all of these issues can be managed effectively, the produce will reach the distribution center, be organized into shipping orders, repackaged, and processed for transport to the individual retail locations.

Supply chains are fluid processes that consist of a number of different components, from producers, vendors and carriers, to category managers, buyers, quality assurance specialists, unloaders and lumpers, pickers, and retail stores. While most people see the piles of produce in the grocery store, and maybe catch the occasional glimpse of the storage room in back, they typically do not consider the scale of the distribution centers and the issues involved in getting product to stores safely and in good condition.
Vendor relationships are a key process for organizing a supply chain. The Company prefers to manage a few large vendors as opposed to a number of smaller independent ones. For the vendor and company, this process offers certain advantages: the Company receives better pricing on volume, and the vendor can track shipments and stock more efficiently. Recently, the Company has been focusing on producing a "top vendors" program to increase volume with those it considers its best vendors and reducing or eliminating business with others. The criteria for best vendor include "best labels," "best varieties," and "best farms." By consolidating vendors, the Company also improves what it calls "over \& above," a program in which if the Company makes its purchasing goals from a vendor, the vendor will pay the Company back 2 percent of the sales. The fewer vendors, the easier it is to make targets and receive the rebate.

The produce chain begins with an order from a buyer to a vendor. The buyers are responsible for purchasing product for the distribution center (DC) from the vendors. These orders are based on inventory levels in the DCs, as well as previous history, current marketing promotions, and purchase orders made by retail stores. Replenishing a $\mathrm{DC}$ is a combined effort among the store managers, buyers, vendors, and carriers. After the buyers make the purchase order, the vendors assemble the product on pallets to be loaded onto the carrier's vehicle. Assuming that the carrier arrives at the vendor's center on time, with no weather or traffic delays, the product can be loaded onto the truck. Here another set of issues begins. Depending on the product, the method for loading the truck can be different.

Key considerations for moving produce include air circulation, temperature control, safety, preventing the cargo from shifting in transit, and ensuring that the pallets used are compatible with the format used at the DC and are safe for loading and unloading. Proper loading of a truck at the vendor's end can dramatically reduce problems at the DC for a number of reasons. First, produce that is packaged properly maintains freshness and quality. Second, by properly loading a truck that is formatted for unloading at a particular DC, the produce will not have to be transferred to new 
pallets or smaller packages, a process known as "lumping." Third, by securing the produce properly, there is less chance that the load will be rejected outright, prompting a claim to either the vendor or carrier, depending on how responsibility is established. Finally, properly positioning the product in the truck promotes air circulation, ensuring even cooling and temperature control.

Temperature is monitored throughout transit by a device called a TempTale, the use of which is highly contested by vendors and carriers because it can determine who is to blame for loss of product quality or the rejection of a load. The TempTale constantly records temperature in the truck digitally. The information is then downloaded at the DC onto a computer, and it is determined if there was any deviation from the appropriate temperature range during transport, which is why correct loading of product and positioning of the TempTale is a key component of the process. The qualityassurance staff then begin to examine the product for freshness, including criteria such as the Brix measurement (sugar content), rot, mold, and stage (i.e., the redness of tomatoes, greenness of bananas). Product specifications are constantly in flux, based on information gathered by technical specialists about what is happening in the various growing regions. For example, if a grape field in Argentina experiences too much rain, which is causing increased waste, the acceptable amount of waste might be increased for the DC. This allows quality-assurance staff to assess product quality accordingly and make adjustments when considering whether to accept or reject the load. The process through which product is accepted or rejected from the DC is designed to ensure that waste is minimized and claims are reduced.

For the Company, efficiency is promoted through this model because the loss of product through rot, or early ripening, is reduced and there are fewer complaints from the stores. If a store receives product from the DC that is too ripe or is rotting, it can file a claim to recover the cost of the product. While the DC is the customer of the vendor, the stores act as customers of the DC. This system allows for a chain of claims to be made, providing that enough information is captured to demonstrate that harm has been caused.
Starting with the DC, category managers and assistant category managers can make claims to their vendors and carriers if quality assurance or receiving staff demonstrates that the product does not meet specified requirements for the produce in question. However, there is a system that must be followed to determine against whom the grievance should be levelled. Starting at receiving, when the truck is backed in and the doors opened, the receiving staff may immediately notice certain issues that could affect the subject of a claim. When the doors open, the staff examine the load to see if it has shifted in transit, whether the TempTale has been placed properly, and the condition of the skids. If there are problems, pictures are taken as evidence to file a claim.

The typical supply chain for the Company is summarized in figure 1.

\section{Locally Sourced Produce}

Within this framework lies the local supply chain, which presents its own logistical problems. Local food can be problematic for the Company to process for two primary reasons. First, producers often do not have the ability to precool their fruits and vegetables with sophisticated and expensive field-chilling equipment, dramatically reducing shelf life. Second, because of the cooling issue, distribution channels must be reorganized to allow the local product to move swiftly through the supply chain in order to reach the retail store in peak condition. According to the Company, additional problems inherent in local food are inadequate information reaching the consumer, failing to time marketing to maximize sales, and mishandling of product through the supply chain. An additional consideration is the organization of business relationships.

The Company conditions for purchasing a product from a local producer are not currently very different from any other purchase, but how the product travels through the supply chain is very different. This process starts with an agreement between the local grower and the Company to provide a particular quantity of a product at a set price. Another method for acquiring locally grown produce is through a farmers' cooperative, which is often the only way smaller growers can access the 
Figure 1. The Company's Existing Supply Chain

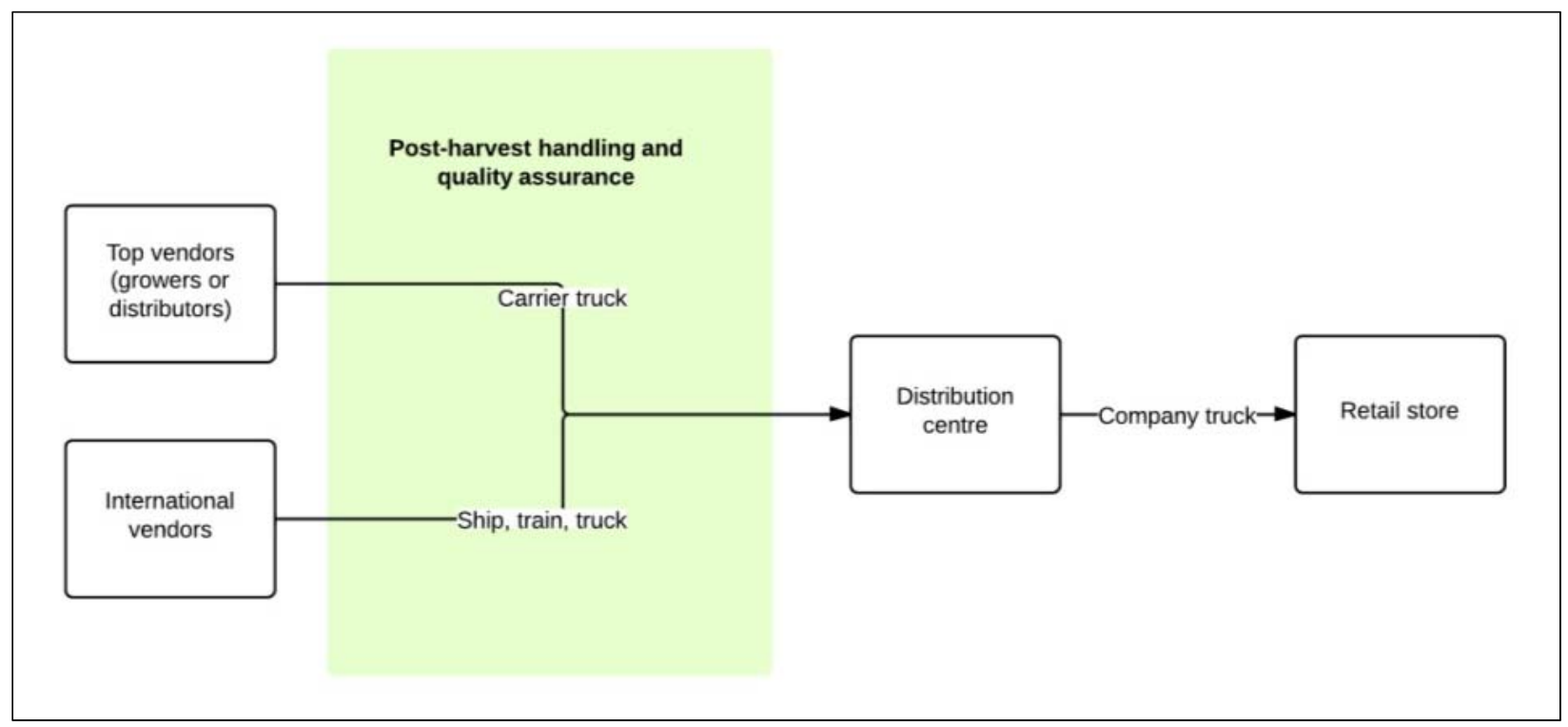

Company. This is because many local growers simply cannot provide enough product volume independently. Successfully integrating local produce in the dominant supply chain depends largely on communication, timing, and marketing (e.g., Bittner et al., 2011; Day-Farnsworth et al., 2009),

The Company purchases and organizes the transfer of local food through four primary mechanisms, which are coordinated between the Company and a vendor, or directly with the grower. The first option is the most simple and straightforward, but probably now rare. The grower delivers the product on his or her own truck from the farm to the distribution center. In this case, the order is filled through a web-based program, which allows the Company to create a purchase order (PO) that the growers see on their computer and thus can immediately fill. The second option is a "back haul." This process requires the Company to coordinate with the grower and one of the Company's transport trucks. The truck is always on its way back from a store delivery, and is rerouted to the grower to pick up the produce requested via the PO. In this instance the grower is charged a fee for the transportation costs of the haul. This is a preferred method for the Company because it allows keeping trucks full. Back haul has been identified in many cases as a significant challenge for innovative local distribution because immature and low volume local markets mean insufficient goods are available for back haul near delivery points (e.g., Bittner et al., 2011; Diamond \& Barham, 2012).

The third and fourth methods rely on third parties to serve as go-betweens for the Company and grower. The transportation division of the Company hires a third-party transport company to coordinate pick-up from the grower and delivery to the DC. This final method is primarily used for delivery from a farmers' cooperative: the grower delivers product to a central location, which then consolidates individual deliveries into pallets to meet the PO of the Company and make one delivery to the DC. This allows smaller growers to access large corporate retailers. Such coops typically have three primary goals: to ensure consistent sales at fair prices, to provide storage and delivery of product to retailers, and to provide liability insurance for members. These preferred approaches for local distribution are summarized in figure 2 .

\section{Volume}

In speaking with the logistics coordinator of the Company, a number of issues were identified as 


\section{Figure 2. Preferable Local Supply Chain}

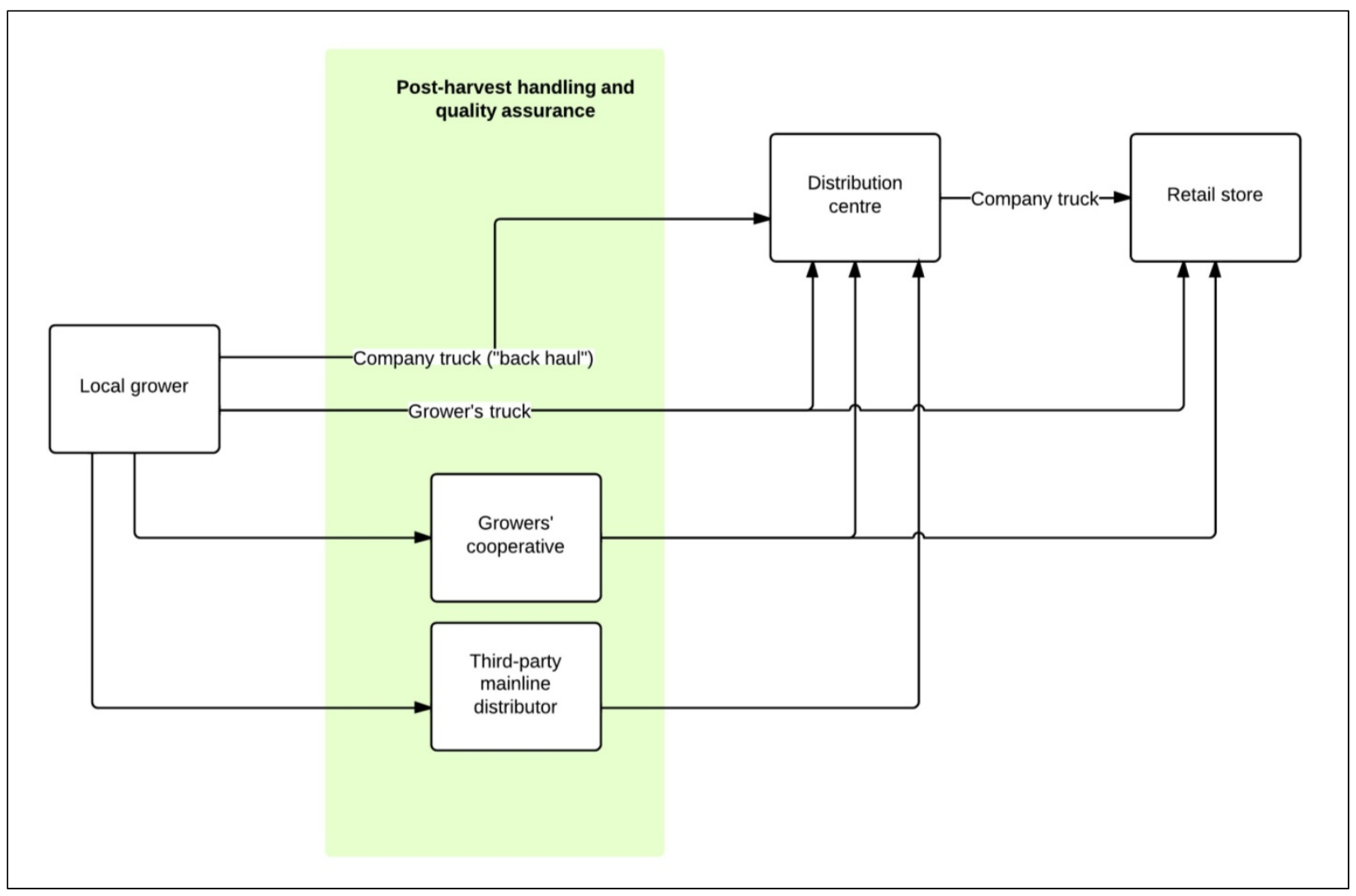

problematic for providing major grocery retailers with local product. On the grower side, the Company encounters issues primarily related to the lack of cooperation among local farmers and their reluctance to join a cooperative. Each farmer believes they have the capacity to handle sales and logistics on their own, and they believe that the stores should sell whatever they grow rather than only product that meets a specific set of criteria. In addition, growers are reluctant to work together because each believes in the superiority of their own product. ${ }^{5}$ This leads farmers to try to sell privately and results in less product being aggregated for large retailers.

This lack of commitment to cooperation is double-sided. Large retailers have no problem making deals with local growers. However, before they sign a contract they need proof of commit-

\footnotetext{
${ }^{5}$ Interpretation provided in an interview with the general manager of an Ontario fruit growers' cooperative.
}

ment from the growers that they will provide the necessary volume of product. Growers, however, are reluctant to agree to pool their product in one place without an agreement from the retailers that they will purchase all of it. To this end, the Company logistics coordinator has suggested that the major obstacle to providing local food in supermarkets, at least for perishable product, is gathering the product of enough growers in one place so that large retail orders can be met.

The challenge of volume is compounded by the complexities of grading. Because the Company is made up of a number of subsidiaries, it arranges different grades of products and different sales prices for each type of store, from discount to high-end stores. Consequently, it orders different grades from different suppliers. Taste, sugar content levels, and product quality are consistent standards that are applied equally regardless of the destination of the product. Size is the primary determining factor for the grade and the type of 
store that will sell it. The farmer may not be able to guarantee the grade of the produce that will be grown; thus, the Company and the farmer might have various levels of price agreements set up prior to harvest. The Company generally needs to make deals with more growers in order to achieve the same volume received from international growers.

\section{Seasonality}

As with other produce, marketing campaigns are planned for seasonal products and their success depends on getting the product from the field to the stores at the time required. Unfortunately, growing seasons are rarely perfect and the product does not always arrive on time. Obviously farmers cannot control the weather or predict with 100 percent accuracy the quality grades of their crops, resulting in occasional delays in harvesting.

In these instances, alternate supplies are arranged ahead of time so that when the Company is notified that the local produce will be late, they can arrange for a back-up shipment. While this is a problem for both grower and supply-chain personnel, according to information received from the Company, the late product from the local vendor is always purchased when it is ready, at the same price agreed upon at the start, provided that the final product meets the same technical standards that were originally agreed to during negotiations. A similar policy is in place for international suppliers.

\section{Cooling}

While coordinating the marketing campaigns with the actual production and delivery of the produce is difficult, getting the product from the field to the store is even more difficult. The inability of local growers to precool their produce prior to shipping means that product immediately loses shelf life, and without being able to move local food quickly, the Company risks a serious loss of revenue. Precooling acts to remove the heat stored in the vegetables during their time in the field. By removing this heat and immediately bringing the temperature of the vegetables down to required specifications, shelf life is increased. This allows companies to take days to ship produce and facilitate transit to the stores. With local food that is not precooled, communication is the key to ensuring fresh produce moves from the field to the store in less than 48 hours. Communication between the carriers from the time they pick up the produce to reception at the DC allows the Company to deal with local, unchilled product immediately by delaying unloading precooled international product and prioritizing the local product. The chain of communication essentially needs to flow from the grower, to the carrier, to the category management team, to the receivers, to the assemblers, to the DC, and finally to the store managers.

\section{Business Relationships}

With these challenges in mind, building a business relationship with its vendors is a primary consideration for the Company due to the impact it can have on volume pricing, proximity to DCs, cost of transport, and production of speciality crops. A number of issues can be either harmful or beneficial to the grower. Depending on the location, volume of goods, and product grown, a grower may have more or less influence over negotiations with the Company, both on pricing and regarding the acceptance or rejection of product at the DC.

First, the location of the grower is certainly a consideration for the Company because of the ease and speed of product transport to the DC. The closer the farm, the easier it is for the Company to call up a last-minute $\mathrm{PO}$ and organize a shipment through the DC to the stores. Additionally, the location of the grower dictates how many obstacles there may be for the Company. The further away the grower, the more complex the transport and logistics. The distance from field to DC not only affects freshness but also creates more chances for weather problems, border disputes, mechanical issues, temperature control issues, increased transport costs, and timing considerations. Growers closer to the DCs can exploit this advantage.

Second, the size of the farm and volume of

\footnotetext{
${ }^{6}$ It is worth noting that the Company logistics coordinator described large corporate retailers as more professional and easier to deal with for local growers than independent grocers, because larger retailers are more willing to pay a premium to have high-quality local product in their stores. In contrast, according to the coordinator, independent retailers constantly demand a lower price for the same quality.
} 
production are considerations for the Company, because fewer growers mean a more streamlined logistics and purchasing process. In corporate terms, this means greater efficiency and lower costs.

Third, the uniqueness and quality of the product grown at the farm influence negotiations with the Company. With fewer local producers of a specific variety or crop, there is more competition between the large supermarket chains for that grower's business. In addition, if that grower can deliver a higher quality product, a higher price can be negotiated.

A senior member of the produce business unit revealed that the Company does take the occasional loss on a local product in order to attract more patrons to the store, hoping that increased purchases in other product categories associated with greater customer volume will compensate for losses associated with purchase of local produce. The benefit of local food, thus, is not necessarily profit, but how a high-quality product draws customers. Nevertheless, while the Company desires to increase its purchase of local food, it needs to see a net revenue increase over time. Without the prospect of profit in this category, the Company believes it would be hard to justify this program to its shareholders.

\section{Discussion and Conclusions}

To summarize, the Company is having difficulty advancing its localization efforts because the requirements of its current produce supply chain are not well suited to the distribution of local product. The value chain model advanced by Stevenson and Pirog (2008) is helpful for understanding why. Derived to meet the unique challenges of local food chains operating at a larger scale, value chains distinguish themselves through four core dimensions: differentiating value-added products; committing to the welfare, particularly financial, of all participants; creating strategic partnerships; and creating trust and shared governance (Bloom \& Hinrichs, 2011). By incorporating these key dimensions, successful value chains are able to "operate at a larger scale than direct marketing while deliberately embedding mechanisms to ensure social, environmental and economic benefits for supply chain participants" (Bloom \&
Hinrichs, 2011, p. 14). Typically, such approaches are associated with midscale and regional food system actors, not major national ones, but we employ the framework here to shed light on challenges facing the Company.

Differentiating local product is particularly challenging for large retail operations that do not have personalized connections in the supply chain. In the Company's view, the success of a local food program, and the ability to purchase increasing quantities of locally grown fruits and vegetables, is largely based on the success of marketing campaigns; however, the promotion of local food at the level of large retail is complex. Scheduling the marketing of products is tricky for the Company due to certain limitations, such as lack of accurate knowledge of when the product will be harvested, little ability to predict product quality, and organizing the regional seasonal differences from one end of the country to another. During the local food season, dozens of products may be available in a relatively short period of time. Because of this, marketing managers must be aware of the potential volume of sales for each product, the price being paid to the producer, and which products they are willing to take a loss on or must make a profit on. Answers to these questions help the marketing department make an informed decision on advertising local produce. After selecting the appropriate products to advertise and brokering a deal with the producer, a timeframe for advertising is arranged based on the producers' predictions for harvest, past experiences, and research collected by the Company.

In general, the food industry has created expectations of constant availability, leaving consumers with the belief that the logistics of moving food around are relatively simple. Now, the Company needs to help consumers understand why local products are only available seasonally, and sometimes inconsistently within the season. The inconsistency is partly about volume, but also represents a structural disconnect between the realities of local growers and supply-chain logistics designed around globalization, including postharvest handling, transport dynamics, and certain quality parameters.

Lack of strategic alliances and conditions of 
trust also create impediments to increasing the volume of local produce available for large retailers. There are certain local products that the Company would like to purchase, but they are not grown in sufficient quantities to warrant distribution at the store level. In particular, Canadian-grown garlic and heirloom tomatoes are products in demand from the Company's customer base; however, because the local quantities are so small and spread out, the Company cannot justify the process of collecting and distributing them to stores. Many farmers are reluctant to switch to these crops because they fear it may not pay off, and retailers are typically unlikely to provide advance contracts to lower the investment risk. This also speaks to the willingness of the Company to assure the financial health of its suppliers. There is some supplydemand coordination going on, and the Company does claim to be paying higher prices, but local farmers likely carry most of the risks associated with losses. The Company does not appear to be willing to support its local grower base with fieldchilling and reliable contracting. In this sense, they do not have strategic alliances with their local grower base and there is no shared governance. The reluctance of many growers to collaborate in cooperatives augments this problem.

Bloom and Hinrichs (2011) report on a distributor "interested in finding ways of securing consistent, reliable relationships with local producers in order to coordinate the supply chain dynamics between production and consumption" (p. 20). There are many things the Company could do if this were its purpose as well. Some firms, such as Gerber, are supporting their grower base more directly now to address this dilemma. They provide technical assistance and favorable contract terms to encourage growers to expand production to meet the specifications of the firm. They also work to aggregate supply and improve product quality. Supporting post-harvest handling with technical assistance and even shared infrastructure would be another valuable investment of the Company in its suppliers. The Company is already supporting family-owned meat suppliers on food safety problems, so having comparable initiatives for produce with post-harvest handling would be consistent with current directions. It would admittedly be challenging to transform supplychain logistics so that the growers could distribute directly to stores, bypassing the DCs, to enhance the likelihood of suitable shelf life, but this would confront current approaches to food safety, product management, and food waste. It would thus appear that localization efforts will not be successful without new mechanisms to overcome these issues.

Comparing the Company's situation to the challenges reported for small to medium-sized retailers, its size, geographic reach, and market dominance appear to present augmented obstacles. Centralized warehousing and the sometimes convoluted movement of food within a region likely increase the gap between harvest and store purchase, with attendant losses of product quality and increased waste. Related to this impediment, a large retailer has the market clout to offload liability for food quality and safety issues onto less powerful local actors, which to some extent contradicts the relationship-building that characterizes many short supply chains. Smaller retailers may also have greater flexibility related to supply seasonality, as they frequently have a less brittle ordering and distribution infrastructure. Their customers may also be more accepting of seasonality relative to large retailers, many of whom have partially built their customer base with year-round access to previously seasonal foods. This case analysis also suggests that a more limited range of local products is likely to be available because of the higher minimum volumes required. A direct comparative study of retailer scale could shed more light on these preliminary conclusions.

\section{References}

Agriculture and Agri-Food Canada [AAFC]. (20032011). An overview of the Canadian agriculture and agrifood system. Retrieved from http://www.agr.gc.ca/ eng/about-us/publications/economicpublications/alphabetical-listing/an-overview-ofthe-canadian-agriculture-and-agri-food-system-2011

AAFC. (2009). Horticulture — Canadian Industry. Retrieved April 1, 2009, from http://www4.agr.gc.ca/ AAFC-AAC/displayafficher.do?id=1184692853496\&lang=eng 
Barham, J. (2009). Assessing alternative food distribution models: Improving marketing opportunities for small-scale and limited-resource producers [PowerPoint presentation]. Washington, D.C.: USDA-AMS Marketing Services Division. http://www.ams.usda.gov/AMSv1.0/getfile?dDoc Name=STELPRDC5076016

Bittner, J., Day-Farnsworth, L., Miller, M., Kozub, R., \& Gollnik, B. (2011). Maximizing freight movements in local food markets. Madison, Wisconsin: National Center for Freight and Infrastructure Research and Education, University of Wisconsin-Madison. http://www.ams.usda.gov/AMSv1.0/getfile?dDoc Name=STELPRDC5097252

Bloom, J. D., \& Hinrichs, C. C. (2011). Moving local food through conventional food food system infrastructure: Value chain framework comparisons and insights. Renewable Agriculture and Food Systems, 26(1), 13-23. http://dx.doi.org/10.1017/S1742170510000384

Born, B., \& Purcell, M. (2006). Avoiding the local trap: Scale and food systems in planning research. Journal of Planning Education and Research, 26(2), 195-207. http://dx.doi.org/10.1177/0739456X06291389

British Columbia Ministry of Agriculture and Lands. (2006). B.C.'s food self-reliance: Can B.C.'s farmers feed our growing population? Victoria, BC: British Columbia Ministry of Agriculture and Lands. Retrieved from http://www.agf.gov.bc.ca/resmgmt/Food_Self_ Reliance/BCFoodSelfReliance Report.pdf

Canadian Organic Growers. (2007). Local and regional food economies in Canada: Status report (Report to Agriculture and Agri-Food Canada). Ottawa: Agriculture and Agri-Food Canada. http://www4.agr.gc.ca/resources/prod/doc/pol/ pub/econ_can/pdf/econ_can_e.pdf

Carter-Whitney, M. (2008). Bringing local food home: Legal, regulatory and institutional barriers to local food. Canadian Institution for Environmental Law and Policy. Toronto: Friends of the Greenbelt Foundation.

Day-Farnsworth, L., McCown, B., Miller, M., \& Pfeiffer, A. (2009). Scaling up: Meeting the demand for local food. Madison, Wisconsin: University of Wisconsin Extension Agricultural Innovation Center and UW Madison Center for Integrated Agricultural Systems, http://www.cias.wisc.edu/wp-content/uploads/ 2010/01/baldwin web final.pdf

Diamond, A., \& Barham, J. (2012). Moving food along the value chain: Innovations in regional food distribution. Washington, D.C.: U.S. Department of Agriculture Marketing Services Division Agricultural Marketing Service.

Edwards-Jones, G., Milà i Canals, L., Hounsome, N., Truninger, M., Koerber, G., Hounsome, B., ...Jones, D. L. (2008). Testing the assertion that "local food is best": The challenges of an evidencebased approach. Trends in Food Science and Technology, 19(5), 265-274.

http://dx.doi.org/10.1016/j.tifs.2008.01.008

Feagan, R. (2007). The place in food: mapping out the "local" in local food systems. Progress in Human Geography, 31(1), 23-42. http://dx.doi.org/10.1177/0309132507073527

Feenstra, G. W., Allen, P., Hardesty, S., Ohmart, J., \& Perez, J. (2011). Using a supply chain analysis to assess the sustainability of farm-to-institution programs. Journal of Agriculture, Food Systems, and Community Development, 1(4), 69-85. http://dx.doi.org/10.5304/jafscd.2011.014.009

Food Links UK. (2006). Best practice in sustainable publicsector food procurement. http://www.localfood.org.uk/ library/Defra-FLUK $\% 20$ best $\% 20$ practice $\% 20$ final $\% 20$ June $\% 2006 . p d f$

Hinrichs, C. (2000). Embeddedness and local food systems: Notes on two types of direct agricultural market. Journal of Rural Studies, 16(3), 295-303. http://dx.doi.org/10.1016/S0743-0167(99)00063-7

Howard, P. H., \& Allen, P. (2006). Beyond organic: Consumer interest in new labeling schemes in the central coast of California. International Journal of Consumer Studies, 30(5), 439-451. http://dx.doi.org/ 10.1111/j.1470-6431.2006.00536.x

Ilbery, B., Morris, C., Buller, H., Maye, D., \& Kneafsey, M. (2005). Product, process and place: An examination of food marketing and labelling schemes in Europe and North America. European Urban and Regional Studies, 12(2), 116-132. http://dx.doi.org/10.1177/0969776405048499

Industry Canada. (2013). Consumer trends update: Canada's changing retail market. Ottawa: Industry Canada.

King, R. P., Hand, M. S., DiGiacomo, G., Clancy, K., Gomez, M. I., Hardesty, S. D.,...McLaughlin, E. W. (2010). Comparing the structure, size, and performance of local and mainstream food supply chains (Economic Research Report No. 99). Washington, D.C.: USDA Economic Research Services. 
Kneafsey, M. (2010). The region in the food: Important or irrelevent? Cambridge Journal of Regions, Economy and Society, 3(2), 177-190.

Kneen, B. (1993). From land to mouth: Understanding the food system. $2^{\text {nd }} \mathrm{ed}$. Toronto: NC Press Limited.

Louden, F. N., \& MacRae, R. (2010). Federal regulation of local and sustainable food labels in Canada: A case study of Local Food Plus. Agriculture and Human Values, 27(2), 177-188. http://dx.doi.org/10.1007/s10460-009-9209-6

MacRae, R., Cuddeford, V., Young, S. B., \& Matsubuchi-Shaw, M. (2013). The food system and climate change: An exploration of emerging strategies to reduce GHG emissions in Canada. Agroecology and Sustainable Food Systems, 37(8), 933963.

http://dx.doi.org/10.1080/21683565.2013.774302

Marsden, T., Banks, J., \& Bristow, G. (2000). Food supply chain approaches: Exploring their role in rural development. Sociologia Ruralis, 40(4), 424-438. http://dx.doi.org/10.1111/1467-9523.00158

Norberg-Hodge, H., Merrifield, T., \& Gorelick, S. (2002). Bringing the food economy home: Local alternatives to global agribusiness. London: Zed.

Pirog, R., Van Pelt, T., Enshayan, K., \& Cook, E. (2001). Food, fuel, and freeways: An Iowa perspective on how far food travels, fuel usage, and greenhouse gas emissions. Ames, Iowa: Iowa State University, Leopold Center for Sustainable Agriculture.

Renting, H., Marsden, T. K., \& Banks, J. (2003). Under- standing alternative food networks: Exploring the role of short food supply chains in rural development. Environment and Planning A, 35(3), 393-411. http://dx.doi.org/10.1068/a3510

Sage, C. (2003). Social embeddedness and relations of regard: Alternative "good food" networks in southwest Ireland. Journal of Rural Studies, 19(1), 47-60. http://dx.doi.org/10.1016/S0743-0167(02)00044X

Stevenson, G. W., \& Pirog, R. (2008). Values-based supply chains: Strategies for agrifood enterprises of the middle. In T. A. Lyson, G. W. Stevenson, \& R. Welsh (Eds.), Food and the mid-level farm: Renewing an agriculture of the middle (pp. 119-145). Cambridge, Massachusetts: MIT Press. http://dx.doi.org/ 10.7551/mitpress /9780262122993.003.0007

Vogt, R. A., \& Kaiser, L. L. (2008). Still a time to act: A review of institutional marketing of regionallygrown food. Agriculture and Human V alues, 25(2), 241-255. http://dx.doi.org/10.1007/s10460-007$\underline{\text { 9106-9 }}$

Weber, C. L., \& Matthews, H. S. (2008). Food miles and the relative climate change impact of food choices in the United States. Environmental Science Technology, 42(10), 3508-3513. http://dx.doi.org/10.1021/es702969f

Winter, M. (2003). Embeddedness, the new food economy and defensive localism. Journal of Rural Studies, 19(1), 23-32. http://dx.doi.org/10.1016/S0743-0167(02)00053-0 